\title{
Effectiveness of exercise and protein supplementation intervention on body composition, functional fitness, and oxidative stress among elderly Malays with sarcopenia
}

\author{
This article was published in the following Dove Press journal: \\ Clinical Interventions in Aging \\ 8 October 2013 \\ Number of times this article has been viewed
}

\author{
Suzana Shahar' \\ Norshafarina Shari \\ Kamaruddin ${ }^{2}$ \\ Manal Badrasawi' \\ Noor Ibrahim Mohamed \\ Sakian ${ }^{3}$ \\ Zahara Abd Manaf' \\ Zaitun Yassin ${ }^{4}$ \\ Leonard Joseph ${ }^{5}$ \\ 'Dietetic Programme, ${ }^{2}$ Biomedical \\ Programme, ${ }^{3}$ Occupational Therapy \\ Programme, School of Healthcare \\ Sciences, Universiti Kebangsaan \\ Malaysia, Jalan Raja Muda Abdul \\ Aziz, Kuala Lumpur, ${ }^{4}$ Department \\ of Nutrition and Dietetics, \\ Faculty of Medicine and Health \\ Sciences, Universiti Putra Malaysia, \\ Serdang, Selangor, ${ }^{5}$ Department of \\ Physiotherapy, School of Healthcare \\ Sciences, Universiti Kebangsaan \\ Malaysia, Jalan Raja Muda Abdul Aziz, \\ Kuala Lumpur, Malaysia
}

Correspondence: Suzana Shahar Dietetic Programme,

School of Healthcare Sciences, Universiti Kebangsaan Malaysia, Jalan Raja Muda Abdul Aziz, 50300 Kuala Lumpur, Malaysia Email suzanas@medic.ukm.my

\begin{abstract}
Sarcopenia, characterized as muscle loss that occurs with aging, is a major health problem in an aging population, due to its implications on mobility, quality of life, and fall risk. Protein supplementation could improve the physical fitness by increasing protein anabolism, and exercise has a documented evidence of positive effect on functional status among the elderly. However, the combined effect of both protein supplementation and exercise has not been investigated among sarcopenic elderly in the Asian population. Thus, this study aimed to determine the effectiveness of exercise intervention and protein supplementation either alone or in combination for 12 weeks, on body composition, functional fitness, and oxidative stress among elderly Malays with sarcopenia. Sixty five sarcopenic elderly Malays aged 60-74 years were assigned to the control group, exercise group (ExG), protein supplementation group ( $\operatorname{PrG})$, or the combination of exercise and protein supplementation group. A significant interaction effect between body weight and body mass index (BMI) was observed, with the PrG $(-2.1 \%$ body weight, $-1.8 \%$ BMI) showing the highest reductions. Further, there was a decrease in $\%$ body fat $(-4.5 \%)$ and an increase in fat-free mass $(\mathrm{kg})(+5.7 \%)$ in the ExG after 12 weeks $(P<0.05)$. The highest increments in lower and upper body strength were observed in the PrG (73.2\%) and ExG (47.6\%), respectively. In addition, the ExG showed a reduction in superoxide dismutase (SOD) levels, and both interventions did not alter either lipid or protein oxidation. In conclusion, the exercise program was found to improve muscle strength and body composition, while protein supplementation reduced body weight and increased upper body strength, among sarcopenic elderly in Malaysia.
\end{abstract}

Keywords: protein supplement, aging population, sarcopenic elderly, Malaysia, Asian

\section{Background}

Aging is associated with muscle loss (sarcopenia) that may adversely affect the quality of life and functional abilities. ${ }^{1,2}$ Sarcopenia is expected to be a health problem among the aging population in Asia. It is important to note that frailty of old age has emerged as an important public health problem because it impairs mobility and quality of life, and increases the risk of falls and the utilization of health care resources. ${ }^{3}$ There is a need to formulate prevention and intervention strategies to deal with sarcopenia. Thus, it is a challenge for society to maintain a high level of physical activity and stay functionally fit to achieve healthy aging.

It is known that muscle strength declines by $15 \%$ per decade after the age of 50 years and by $30 \%$ per decade after the age of 70 , leading to sarcopenia. ${ }^{4}$ The prevalence 
of sarcopenia varies from $6 \%$ to $24 \%$, depending on the geographical location, diagnostic tool, and cutoff points used. ${ }^{5,6}$ Physical inactivity and inadequate protein intake have been recognized to contribute to sarcopenia. ${ }^{7-9}$ Furthermore, oxidative stress can trigger sarcopenia by increasing reactive oxygen species with aging, which can decrease muscle performance and muscle mass. ${ }^{10}$

It has been demonstrated that regular exercise is effective for maintaining and promoting health, physical fitness, and functional independence in older adults, especially in terms of endurance, muscular strength, flexibility, and balance. ${ }^{11}$ It is known that resistance and aerobic exercise might help in delaying muscle deterioration, which can progress to sarcopenia in the elderly. However, aerobic exercise alone does not contribute much to the improvement of muscle mass strength as compared with resistance training. ${ }^{12}$ Resistance training increases muscle mass and strength, due to the increase in the rate of synthesis of myosin heavy-chain and mixed muscle protein, and increase in muscle fiber size as well as in capillary density in the muscle. ${ }^{13}$

Dietary protein supplementation is easily administered and with relatively low cost. It can be used in almost all aging populations, and it is intuitively and theoretically appropriate. It can increase daily protein and energy intake. ${ }^{14}$ Yet, the appropriate amount of protein supplementation needed to increase functional fitness has not been standardized and ranges from $1.2 \mathrm{~g} / \mathrm{kg} /$ day to $1.5 \mathrm{~g} / \mathrm{kg} /$ day. Protein supplementation can also increase protein anabolism, including protein synthesis, as well as metabolic and physical status in elderly subjects with sarcopenia. In particular, an addition of resistance exercise to protein supplementation could increase muscle size and strength in elderly people. ${ }^{15}$

Recognizing the importance of a lifestyle that would prevent the delay of muscle loss, previous studies have been conducted to determine the benefit of exercise and nutrition intervention among older adults. ${ }^{16,17}$ Nevertheless, to our best knowledge, the current study is the only one using an exercise intervention and protein supplementation to reduce sarcopenia among elderly Malays with sarcopenia. Although community-based, well-rounded exercise programs have been proven to improve muscle mass and functional fitness, their efficacy in reversing sarcopenia has not been documented. Furthermore, the beneficial effects of a combination of wellrounded exercise and protein supplementation in improving body composition, physical function, and oxidative stress among sarcopenic elderly has yet to be determined. Thus, this study aimed to determine the beneficial effects of exercise and protein supplementation, either alone or in combination, on the improvement of body composition, physical fitness, and oxidative stress among community-dwelling elderly people aged 60 years and above, with sarcopenia. It was hypothesized that a well-rounded exercise program and protein supplementation could improve body composition, physical fitness, and oxidative stress among elderly people with sarcopenia. This study is a part of a larger community-based intervention (the Warga Emas Sihat Program) that aims to improve the health of the Malaysian elderly people.

\section{Methodology Study design}

This was a quasi-experimental, community-based intervention study, carried out from February 2010 to May 2010. A total of 65 sarcopenic subjects (men, $n=47$; women, $\mathrm{n}=18$ ) were identified in the screening phase among 388 older adults (men, $\mathrm{n}=155$; women, $\mathrm{n}=233$ ) residing in low-cost flats and houses in Cheras, Kuala Lumpur (the capital city of Malaysia). The subjects were divided into four groups according to the intervention and study location (senior citizen clubs in Jalan Siakap, Bandar Tun Razak, Seri Labuan, and Sri Sabah): the control group (CG), exercise group (ExG), protein supplementation group (PrG), and combined exercise and protein supplementation group $(\mathrm{Ex}+\mathrm{PrG})$. The inclusion criteria were: elderly people aged 60 years old and above with sarcopenia (assessed using bioimpedance analysis, with the skeletal muscle cutoff points of less than $10.75 \mathrm{~kg} / \mathrm{m}^{2}$ for men and $6.75 \mathrm{~kg} / \mathrm{m}^{2}$ for women, as suggested by Janssen et $\mathrm{al}^{5}$ ); permanent residents for at least 1 year prior to study, and with no terminal illness that could have limited their involvement and compliance to the intervention. Subjects who had been regularly consuming protein and dietary supplementation for the 3 months prior to the study and those with unstable chronic diseases were excluded. All participants were fully informed about the study and signed a consent form. The Institutional Review Boards of all participating senior citizen clubs approved the study.

The participants were gathered at community halls of the respective study locations for sociodemographic data collection (including sex, age, marital status, educational level, and employment) and health profiling. At baseline (1 week prior to the intervention), the primary outcomes (anthropometry and body composition) and secondary outcomes (fitness test and functional fitness) were measured. A $10 \mathrm{~mL}$ venous blood sample was drawn from the antecubital vein, with the subject in a seated position, after an overnight fast. The samples were centrifuged at $28,000 \mathrm{~g}$ for 5 minutes at $4{ }^{\circ} \mathrm{C}$, the clear supernatants were collected, and plasma was stored 
in multiple aliquots at $-30^{\circ} \mathrm{C}$. A dietary intake assessment was also done at the baseline visit, using a validated diet history questionnaire interrogating for habitual food intake, dietary pattern, and cooking methods. ${ }^{18}$

\section{The intervention}

The exercise group received approximately 60 minutes of moderately intensive, well-rounded activities in facilitated group sessions, held twice a week for 12 weeks at a local community center to ensure that participants would use the correct/recommended exercise techniques. These sessions were conducted by trained exercise instructors and supervised by the researchers. A pictorial guidebook and a compact disc (CD) were provided to each participant to assist them in performing the same exercise regimen, either at the center or at home. Participants were encouraged to do exercise at home. The pictorial guidebook and the CD were developed by the researchers, using trained fitness instructors and older adults as models. The program started with 10 minutes of general warm-up/aerobic exercises, including: walking and jogging on the spot; walking forwards, backwards, and sideways; arm movements; raising the head and moving it in a circular manner; moving the trunk in four directions; and pushing the knee forwards and backwards. This was followed by seven simple balance exercises, in which the participants were asked to stand on their heels; stand on one leg with the other leg on the ground or lifted behind or aside; stand on one leg while lifting up the opposite hand; and to walk foot by foot with fingers touching the foot from the back. Then, 30 minutes of resistance exercises were done, using an elastic band (TheraBand ${ }^{\circledR}$ exercise bands, Hygenic Corporation, $\mathrm{OH}$, USA) and included: shoulder abduction; shoulder flexion; overhead press and side lateral extension; a standing double biceps curl; triceps extension; leg extension; foot extension; and plantar flexion. Finally, cool down/relaxation exercises were done for 10 minutes. The intensity of the resistance exercise was adjusted according to individual performance by changing the color of the elastic band, which had different tension levels.

The protein supplementation group received a soy protein drink (Cosway (M) Sdn. Bhd., Kuala Lumpur, Malaysia) in a powder form to maintain the protein intake of the subjects at up to $1.5 \mathrm{~g} / \mathrm{kg} /$ day. According to Wolfe et al, ${ }^{15}$ a total of $1.5 \mathrm{~g} /$ $\mathrm{kg} /$ day can increase muscle mass and functional fitness. The energy composition of the protein supplementation contained $23 \%$ protein, $0.8 \%$ fat, and $0.3 \%$ carbohydrates. This protein supplementation was chosen because it has a high portion of protein, especially leucine, since leucine is required in a high proportion for optimal stimulation of the rate of muscle protein synthesis in the elderly. ${ }^{19}$

The mean protein intake of subjects at baseline was $56.7 \mathrm{~g} /$ day in men and $52.5 \mathrm{~g} /$ day in women. An additional amount, $20 \mathrm{~g} /$ day and $40 \mathrm{~g} /$ day, of high protein supplementation in a powder form was given to men and women subjects, respectively. The subjects were asked to take the supplement once per day and to record their intake in a log book. The researchers provided the protein supplements once a week to the subjects, at the allocated community center. The compliance was calculated through the sachets returned by the subjects to the researchers every week. The CG received a relaxation exercise program every 2 weeks for 3 months, supervised by the researchers, to maintain the interaction and increase the motivation of the subjects during the intervention.

\section{Study instruments Body composition measurement}

Anthropometric parameters were measured, including: body weight, to the nearest $0.1 \mathrm{~kg}$, using a Tanita Digital Lithium Scale HD319 (Tanita Corp, Tokyo, Japan); height, using SECA Leicester Portable Height Measure (Seca GmbH and Co, Hamburg, Germany); and waist circumference, using a Seca measuring tape, to the nearest $0.1 \mathrm{~cm}$. A Maltron Bio-Scan 916 (Maltron International Ltd, Rayleigh, UK) was used for measurement of body composition and it uses a bioimpedance analysis method.

\section{Senior Fitness Test (SFT)}

Subjects carried out a 10-minute warm up exercise led by an instructor, and then they completed the SFT by Jones and Rikli. ${ }^{20}$ The test consists of six measurements of physical fitness: (1) the Chair Stand Test assesses lower-body strength and was scored as the total number of stands executed correctly within 20 seconds; (2) the Arm Curl Test was used to assess upper body strength and was scored as the number of repetitions completed within 30 seconds; (3) the Chair Sit and Reach Test evaluates lower body flexibility and was scored as the number of centimeters short of reaching the toes (minus score) or beyond the toes (plus score); (4) the Back Scratch Test measures upper body flexibility and was scored as the number of centimeters the middle fingers were short of touching (minus score) or overlapped each other (plus score); (5) the 8-Foot Up and Go Test was used to assess dynamic balance, and for this test, the best performance time of the test trials was recorded, to 0.1 second; and finally, (6) the six-minute Walk Test which evaluates aerobic endurance, also was done and was scored as the total number of 
meters walked in 6 minutes. ${ }^{21}$ In addition, handgrip strength was assessed as an estimate of muscle strength; functional fitness (handgrip strength) was measured using a pinchgrip Dynamometer (JAMAR Hydraulic Hand Dynamometer; Patterson Medical Holdings, Inc, Bolingbrook, IL,USA) to the nearest $0.1 \mathrm{~kg}$.

\section{Oxidative stress and hormone markers}

The plasma was thawed once for the ascertainment of oxidative stress markers, such as superoxide dismutase enzyme (SOD), ${ }^{22}$ and protein carbonyl. ${ }^{23}$ SOD was determined using the Beyer and Fridovich method (assaying for superoxide dismutase using spectrophotometry). ${ }^{22}$ Protein carbonyl was determined using the Buss et al method for protein carbonyl measurement. ${ }^{23}$ Lipid hydroperoxide was determined using a kit by Cayman Chemical (Ann Arbor, MI, USA), and glutathione was determined using a Merck kit (Calbiochem ${ }^{\circledR}$; Merck KGaA Darmstadt, Germany), respectively. The determination of insulin-like growth factor (IGF)-1 and orexin was done using an enzyme-linked immunosorbent assay (ELISA) kit by Cell Sciences $^{\circledR}$ (Cell Sciences Inc, Canton, MA, USA), and for interleukin (IL)-6, by an enzyme immunoassay (EIA) by Bachem (Bachem/Peninsula Laboratories, Inc., San Carlos, CA, USA).

\section{Statistical analysis}

Statistical Package for Social Sciences for Windows, Version 17 (IBM Corporation, Armonk, NY, USA) was used to analyze the data collected. Descriptive analysis was performed on demographic data, body composition, SFT results, and the oxidative stress and hormone markers. A one-way analysis of variance (ANOVA) and chi-square tests were used to compare between the intervention groups at baseline. Since the data was normally distributed, as proven by the Shapiro-Wilk test, a two-factor analysis of covariance (ANCOVA) was used to compare the body composition, functional fitness, and oxidative stress between intervention groups adjusted for sex and sarcopenia status (sarcopenia, lean, and obese). All tests were two-tailed, at a probability level of 0.05 .

\section{Results}

A total of 65 subjects (men, $n=47$; women, $n=18$ ) completed the intervention program, with a response rate of $86.7 \%$. About ten participants failed to complete the intervention during the first few weeks of program because of various reasons, such family commitments, health problems, absence in the follow-up investigation period, and being busy with daily activities.

\section{Subjects' sociodemographic data}

The baseline characteristics of the 65 participants (mean age $67.1 \pm 5.3$ years) are presented in Table 1 . Only $7.7 \%$ of subjects were working; only $12.3 \%$ were married and $87.7 \%$ were either single or a widow/widower. About $17.2 \%$ had no formal education, while $82.8 \%$ had formal education (completed middle and high school). Also, $13.8 \%$ had a history of geriatric falls. There were no

Table I Baseline characteristic according to intervention group

\begin{tabular}{|c|c|c|c|c|c|}
\hline \multirow[t]{3}{*}{ Baseline characteristics } & \multicolumn{4}{|l|}{ Study groups } & \multirow{3}{*}{$\begin{array}{l}\text { ANCOVA (two-way) } \\
\text {-value }\end{array}$} \\
\hline & CG & ExG & PrG & ExG+PrG & \\
\hline & $n=16$ & $n=19$ & $n=15$ & $n=15$ & \\
\hline Age (year) & $67.25 \pm 5.48$ & $69.74 \pm 5.46$ & $65.93 \pm 4.37$ & $65.20 \pm 4.87$ & 0.083 \\
\hline Weight (kg) & $67.36 \pm 11.88$ & $60.49 \pm 10.66$ & $61.39 \pm 12.73$ & $65.53 \pm 12.40$ & 0.203 \\
\hline $\mathrm{BMI}\left(\mathrm{kg} / \mathrm{m}^{2}\right)$ & $26.36 \pm 3.19$ & $23.7 I \pm 3.46$ & $24.26 \pm 4.37$ & $26.47 \pm 4.75$ & 0.103 \\
\hline Body fat (\%) & $28.82 \pm 6.89$ & $25.25 \pm 6.57$ & $27.51 \pm 9.17$ & $31.97 \pm 9.62$ & 0.079 \\
\hline FFM (kg) & $48.68 \pm 8.1$ & $44.4 \pm 7.4$ & $44.0 \pm 8.1$ & $43.9 \pm 7.7$ & 0.276 \\
\hline Muscle (kg) & $22.94 \pm 5.29$ & $20.95 \pm 4.23$ & $20.57 \pm 4.70$ & $20.73 \pm 4.69$ & 0.462 \\
\hline Body water (\%) & $55.77 \pm 4.04$ & $57.91 \pm 3.42$ & $56.29 \pm 4.96$ & $53.75 \pm 5.17$ & 0.370 \\
\hline IADL score & $7.59 \pm 0.88$ & $7.37 \pm 0.89$ & $8.00 \pm 0.00$ & $7.53 \pm 0.64$ & 0.094 \\
\hline IPAQ score & $1699.35 \pm 153.49$ & $1330.48 \pm 954.33$ & $1467.20 \pm 842.66$ & $1479.18 \pm 724.35$ & 0.691 \\
\hline Calorie (Kcal) & $1377.76 \pm 153.49$ & $|452.70 \pm 192.9|$ & $1320.86 \pm 1 \mid 1.43$ & $1377.76 \pm 153.49$ & 0.132 \\
\hline Carbohydrate (Kcal) & $191.75 \pm 27.10$ & $225.81 \pm 35.55$ & $187.80 \pm 22.89$ & $199.23 \pm 22.65$ & $0.00 I^{*}$ \\
\hline Protein (g) & $61.07 \pm 9.32$ & $54.89 \pm 8.86$ & $49.96 \pm 11.70$ & $55.63 \pm 5.85$ & $0.014^{*}$ \\
\hline Fat $(g)$ & $40.79 \pm 10.39$ & $36.05 \pm 4.72$ & $41.15 \pm 6.40$ & $39.32 \pm 10.91$ & 0.261 \\
\hline
\end{tabular}

Notes: Values are expressed as mean \pm SD. $* P<0.05$ is significant with baseline measurement used as covariates on ANCOVA analysis.

Abbreviations: ANCOVA, analysis of covariance; BMI, body mass index; CG, control group; ExG, exercise group; ExG+PrG, combined exercise and protein supplementation group; FFM, fat-free mass; IADL, instrumental activity of daily living; IPAQ, international physical activity questionnaire; PrG, protein suplementation group; SD, standard deviation. 
significant differences with respect to sociodemography, health profile, or health practices between the intervention groups.

\section{Intervention effect on nutritional status and body composition}

There were significant differences in carbohydrate and protein intake among the groups at baseline $(P<0.05)$; thus these parameters were included as covariates in the analysis. An improvement in body composition following the intervention was observed in this current study. After the 12-week intervention, significant interaction effects were noted for body weight $\left(F_{3,61}=2.467\right)(P<0.05)$, body mass index (BMI) $\left(F_{3,61}=2.278\right)(P<0.05), \%$ body fat $\left(F_{3,61}=2.567\right)$ $(P<0.05), \%$ fat-free mass $\left(F_{3,61}=3.281\right)(P<0.05)$, and $\%$ total body water $\left(F_{3,61}=4.609\right)(P<0.05)$. A time effect was seen for BMI $\left(F_{3,61}=3.647\right)(P<0.05)$ and $\%$ total body water $\left(F_{3,61}=6.215\right)(P<0.05)$, while a group effect was seen for $\%$ total body water $\left(F_{3,61}=3.413\right)(P<0.05)$ (Table 2$)$. It was found that the $\operatorname{PrG}$ group had the largest decrease in body weight $(\Delta-2.1 \%)$ and BMI $(-1.8 \%)$ throughout the 12-week intervention as compared with baseline. The ExG showed a decrease in body fat $(-11.6 \%)$ and an increase in fat-free mass $(+5.1 \%)$ during the 12 -week intervention as compared with baseline.

\section{Intervention effect on physical fitness parameters}

As shown in Table 3, there was an interaction effect for the Chair Stand Test $\left(F_{3,61}=3.833\right)(P<0.05)$, Arm Curl Test $\left(F_{3,61}=4.282\right)(P<0.05)$, and the 8-Foot Up and Go Test $\left(F_{3,61}=2.737\right)(P<0.05)$. A significant group effect was noted for the Chair Stand Test $\left(F_{3,61}=7.533\right)(P<0.05)$ and $\operatorname{Arm} \operatorname{Curl}\left(F_{3,61}=6.310\right)(P<0.05)$, and a time effect for the Chair Stand Test $\left(F_{3,61}=11.123\right)(P<0.05)$ and Arm Curl Test $\left(F_{3,61}=7.082\right)(P<0.05)$. With respect to the Chair Stand Test, the PrG (+73.2\%) showed the highest increment, followed by the ExG + PrG (+62.8\%) and ExG (23.8\%) compared with the CG $(+10.3 \%)$, at 12 weeks (Figure 1). Furthermore, for the Arm Curl Test (indicating upper arm

Table 2 Profile of anthropometry and body composition at baseline, 6 weeks, and 12 weeks of intervention, according to intervention group

\begin{tabular}{|c|c|c|c|c|c|c|c|}
\hline \multirow{2}{*}{$\begin{array}{l}\text { Anthropometric } \\
\text { measurement }\end{array}$} & \multicolumn{4}{|l|}{ Study groups } & \multicolumn{3}{|c|}{ ANCOVA (two-way) } \\
\hline & $\begin{array}{l}\text { CG } \\
n=16\end{array}$ & $\begin{array}{l}\text { ExG } \\
n=19\end{array}$ & $\begin{array}{l}\text { PrG } \\
n=15\end{array}$ & $\begin{array}{l}\text { ExG+PrG } \\
n=15\end{array}$ & $\begin{array}{l}\text { Group } \\
\text { effect }\end{array}$ & $\begin{array}{l}\text { Time } \\
\text { effect }\end{array}$ & $\begin{array}{l}\text { Interaction } \\
\text { effect }\end{array}$ \\
\hline \multicolumn{8}{|l|}{ Weight (kg) } \\
\hline Baseline & $67.36 \pm 11.88$ & $59.49 \pm 10.66$ & $61.39 \pm 12.73$ & $65.53 \pm 12.40$ & 0.404 & 0.083 & $0.027)$ \\
\hline 6 weeks & $63.98 \pm 10.44$ & $59.03 \pm 10.28$ & $63.12 \pm 11.16$ & $66.43 \pm 12.56$ & $(0.048)$ & $(0.04 I)$ & $(0.112)$ \\
\hline 12 weeks & $65.99 \pm 10.85$ & $59.78 \pm 10.89$ & $60.11 \pm 11.48$ & $66.18 \pm 12.70$ & & & \\
\hline \multicolumn{8}{|l|}{ BMI $\left(\mathrm{kg} / \mathrm{m}^{2}\right)$} \\
\hline Baseline & $26.36 \pm 3.19$ & $23.7 \mathrm{I} \pm 3.46$ & $24.26 \pm 4.37$ & $26.47 \pm 4.75$ & 0.315 & $0.029 *$ & $0.04 I^{*}$ \\
\hline 6 weeks & $25.31 \pm 2.47$ & $23.38 \pm 3.03$ & $24.87 \pm 3.48$ & $26.47 \pm 4.52$ & $(0.058)$ & $(0.058)$ & $(0.104)$ \\
\hline 12 weeks & $25.91 \pm 2.96$ & $23.93 \pm 3.61$ & $23.82 \pm 4.16$ & $26.45 \pm 4.65$ & & & \\
\hline \multicolumn{8}{|l|}{ Body fat (\%) } \\
\hline Baseline & $28.82 \pm 6.89$ & $25.25 \pm 6.57$ & $27.51 \pm 9.17$ & $31.97 \pm 9.62$ & 0.332 & 0.480 & $0.023^{*}$ \\
\hline 6 weeks & $25.67 \pm 8.38$ & $24.32 \pm 6.34$ & $28.41 \pm 9.89$ & $29.69 \pm 10.89$ & $(0.056)$ & $(0.012)$ & $(0.115)$ \\
\hline 12 weeks & $27.83 \pm 6.99$ & $22.32 \pm 9.93$ & $27.37 \pm 10.30$ & $32.28 \pm 9.64$ & & & \\
\hline \multicolumn{8}{|l|}{$\mathrm{FFM}(\mathrm{kg})$} \\
\hline Baseline & $48.60 \pm 8.07$ & $44.38 \pm 7.38$ & $44.02 \pm 8.14$ & $43.96 \pm 7.74$ & 0.209 & 0.184 & $0.005^{*}$ \\
\hline 6 weeks & $46.38 \pm 8.15$ & $45.04 \pm 7.73$ & $44.67 \pm 7.52$ & $46.08 \pm 8.72$ & $(0.073)$ & $(0.028)$ & $(0.143)$ \\
\hline 12 weeks & $47.73 \pm 7.39$ & $46.74 \pm 8.13$ & $43.09 \pm 7.61$ & $44.09 \pm 8.57$ & & & \\
\hline \multicolumn{8}{|l|}{ Muscle (kg) } \\
\hline Baseline & $22.94 \pm 5.29$ & $20.95 \pm 4.23$ & $20.57 \pm 4.70$ & $20.73 \pm 4.69$ & 0.574 & 0.384 & 0.111 \\
\hline 6 weeks & $20.98 \pm 5.27$ & $20.82 \pm 4.23$ & $21.49 \pm 4.11$ & $21.98 \pm 5.26$ & $(0.033)$ & $(0.016)$ & $(0.083)$ \\
\hline 12 weeks & $22.68 \pm 4.22$ & $21.29 \pm 4.64$ & $20.29 \pm 4.31$ & $21.02 \pm 5.11$ & & & \\
\hline \multicolumn{8}{|l|}{ Body water (\%) } \\
\hline Baseline & $55.05 \pm 4.04$ & $57.91 \pm 3.42$ & $56.29 \pm 4.96$ & $53.75 \pm 5.17$ & 0.006 & 0.036 & 0.000 \\
\hline 6 weeks & $63.83 \pm 13.84$ & $58.22 \pm 3.62$ & $52.92 \pm 8.75$ & $55.73 \pm 6.08$ & $(0.190)$ & $(0.055)$ & $(0.240)$ \\
\hline 12 weeks & $56.3 I \pm 3.5 I$ & $65.46 \pm 12.21$ & $55.59 \pm 5.68$ & $53.27 \pm 4.87$ & & & \\
\hline
\end{tabular}

Notes: Values are expressed as mean $\pm S D$. $* P<0.05$ significant effect using ANCOVA, with sarcopenia status and sex as covariates.

Abbreviations: ANCOVA, analysis of covariance; BMI, body mass index; CG, control group; ExG, exercise group; ExG+PrG, combined exercise and protein supplementation group; FFM, fat-free mass; PrG, protein suplementation group; SD, standard deviation. 
Table 3 Functional fitness test at baseline, 6 weeks, and I 2 weeks of intervention, according to intervention groups

\begin{tabular}{|c|c|c|c|c|c|c|c|}
\hline \multirow{2}{*}{$\begin{array}{l}\text { Functional } \\
\text { fitness test }\end{array}$} & \multicolumn{4}{|l|}{ Study groups } & \multicolumn{3}{|c|}{ ANCOVA (two-way) } \\
\hline & $\begin{array}{l}\text { CG } \\
n=16\end{array}$ & $\begin{array}{l}\text { ExG } \\
n=19\end{array}$ & $\begin{array}{l}\text { PrG } \\
n=15\end{array}$ & $\begin{array}{l}\text { ExG+PrG } \\
n=15\end{array}$ & $\begin{array}{l}\text { Group } \\
\text { effect }\end{array}$ & $\begin{array}{l}\text { Time } \\
\text { effect }\end{array}$ & $\begin{array}{l}\text { Interaction } \\
\text { effect }\end{array}$ \\
\hline \multicolumn{8}{|c|}{ Chair Stand Test (times) } \\
\hline Baseline & $11.23 \pm 4.44$ & $14.29 \pm 4.95$ & $9.60 \pm 2.26$ & $10.32 \pm 3.01$ & $0.000 *$ & $0.000 *$ & $0.002 *$ \\
\hline 6 weeks & $12.15 \pm 3.37$ & $16.19 \pm 4.67$ & $\mid \mathrm{I} .42 \pm 2.4 \mathrm{I}$ & $16.53 \pm 3.31$ & $(0.280)$ & $(0.161)$ & $(0.165)$ \\
\hline 12 weeks & $12.39 \pm 4.17$ & $17.69 \pm 6.54$ & $16.63 \pm 3.03$ & $16.80 \pm 3.93$ & & & \\
\hline \multicolumn{8}{|c|}{ Arm Curl Test (times) } \\
\hline Baseline & $18.39 \pm 5.88$ & $12.20 \pm 3.42$ & $11.47 \pm 2.89$ & $13.39 \pm 2.25$ & & & \\
\hline 6 weeks & $19.92 \pm 8.42$ & $23.17 \pm 6.73$ & $15.95 \pm 3.37$ & $24.87 \pm 6.16$ & $0.033^{*}$ & $0.001 *$ & $0.001 *$ \\
\hline 12 weeks & $16.37 \pm 4.02$ & $\mid 8.01 \pm 5.70$ & $15.68 \pm 2.52$ & $18.53 \pm 3.76$ & $(0.186)$ & $(0.109)$ & $(0.18 I)$ \\
\hline \multicolumn{8}{|c|}{ Chair Sit and Reach (mm) } \\
\hline Baseline & $5.87 \pm 12.85$ & $5.17 \pm 11.98$ & $1.52 \pm 14.07$ & $-3.27 \pm 10.00$ & & & \\
\hline 6 weeks & $5.29 \pm 3.06$ & $11.16 \pm 6.48$ & $3.43 \pm 11.68$ & $2.57 \pm 7.81$ & 0.065 & 0.576 & 0.414 \\
\hline 12 weeks & $0.32 \pm 10.50$ & $2.60 \pm 8.43$ & $-2.53 \pm 7.76$ & $-1.40 \pm 8.53$ & $(0.1 \mid 4)$ & $(0.009)$ & $(0.049)$ \\
\hline \multicolumn{8}{|c|}{ Backscratch (mm) } \\
\hline Baseline & $-9.98 \pm 16.67$ & $-2.02 \pm 12.16$ & $-11.89 \pm 13.19$ & $-10.36 \pm 10.38$ & & & \\
\hline 6 weeks & $-13.53 \pm 11.39$ & $-9.82 \pm 9.70$ & $-|0.89 \pm| 4.4 \mid$ & $-2.03 \pm 17.84$ & 0.252 & 0.542 & 0.112 \\
\hline 12 weeks & $-20.07 \pm 12.66$ & $-16.83 \pm 9.65$ & $-18.18 \pm 8.45$ & $-20.27 \pm 12.38$ & $(0.066)$ & $(0.010)$ & $(0.082)$ \\
\hline \multicolumn{8}{|c|}{ 8-Foot Up and Go (s) } \\
\hline Baseline & $7.34 \pm 2.36$ & $8.54 \pm 2.41$ & $8.26 \pm 1.91$ & $8.39 \pm 0.83$ & & & \\
\hline 6 weeks & $7.39 \pm 1.61$ & $6.55 \pm 1.20$ & $7.73 \pm 1.38$ & $5.95 \pm 1.44$ & 0.336 & 0.567 & $0.016^{*}$ \\
\hline 12 weeks & $8.65 \pm 5.53$ & $6.69 \pm 1.85$ & $5.92 \pm 4.92$ & $6.16 \pm 1.39$ & $(0.055)$ & $(0.010)$ & $(0.122)$ \\
\hline \multicolumn{8}{|c|}{ Six-minute Walk (m) } \\
\hline Baseline & $343.48 \pm 117.99$ & $360.66 \pm 162.03$ & $335.97 \pm 87.63$ & $321.17 \pm 49.75$ & & & \\
\hline 6 weeks & $349.38 \pm 88.19$ & $400.82 \pm 85.07$ & $380.31 \pm 63.80$ & $366.86 \pm 54.83$ & 0.462 & 0.481 & 0.939 \\
\hline 12 weeks & $359.18 \pm 152.93$ & $412.71 \pm 136.49$ & $360.71 \pm 93.23$ & $377.23 \pm 53.96$ & $(0.042)$ & $(0.012)$ & $(0.015)$ \\
\hline \multicolumn{8}{|c|}{ Handgrip Strength (kg) } \\
\hline Baseline & $21.42 \pm 8.41$ & $20.37 \pm 5.64$ & $19.75 \pm 9.02$ & $20.80 \pm 8.23$ & & & \\
\hline 6 weeks & $19.53 \pm 6.85$ & $20.18 \pm 5.49$ & $18.02 \pm 7.03$ & $24.33 \pm 7.68$ & 0.140 & 0.124 & 0.167 \\
\hline 12 weeks & $18.64 \pm 5.46$ & $19.03 \pm 6.32$ & $|6.87 \pm 7.6|$ & $19.27 \pm 6.92$ & $(0.088)$ & $(0.035)$ & $(0.073)$ \\
\hline
\end{tabular}

Notes: Values are expressed as mean \pm SD. $* P<0.05$ significant effect using ANCOVA with sarcopenia status and sex as covariates.

Abbreviations: ANCOVA, analysis of covariance; CG, control group; ExG, exercise group; ExG+PrG, combined exercise and protein supplementation group; PrG, protein suplementation group; SD, standard deviation.

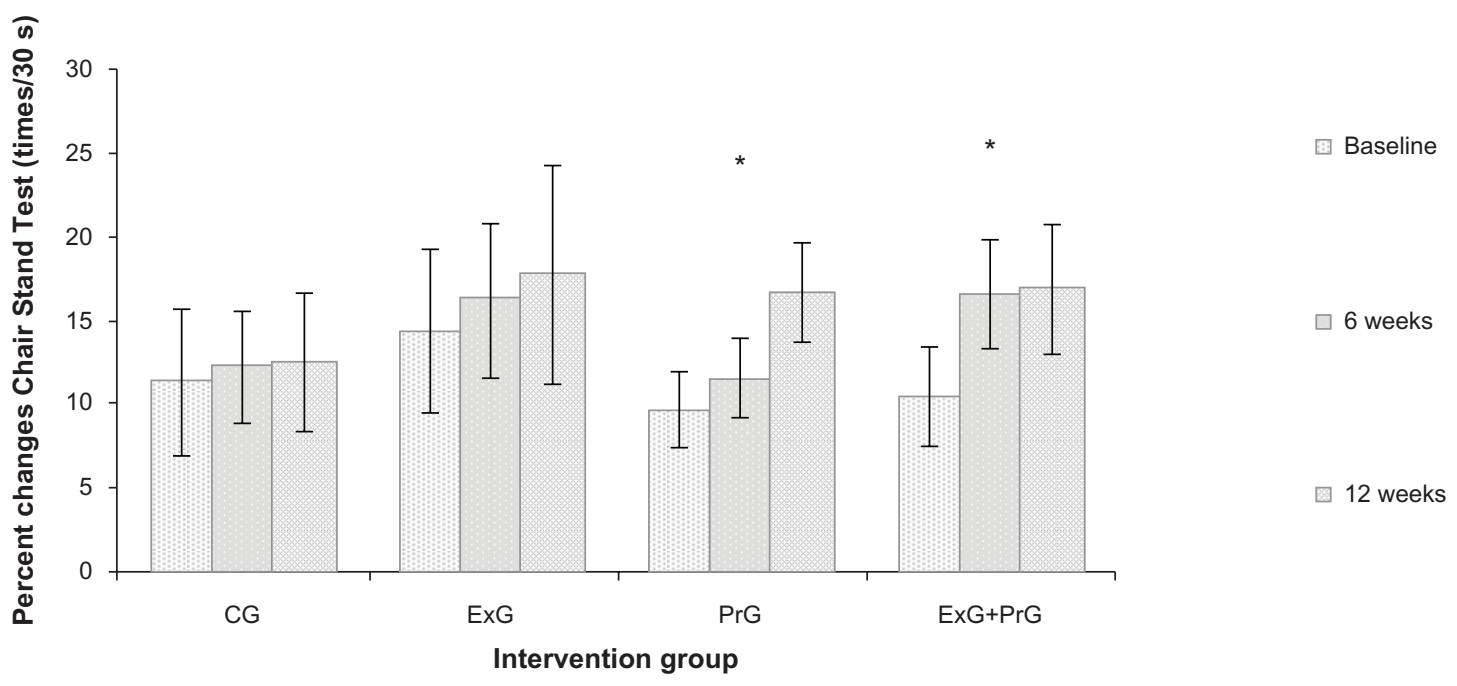

Figure I Percent changes in Chair Stand Test results, in the different intervention groups during the 12-week intervention. Notes: Values are expressed as mean \pm SD. *Significant differences at $P<0.05$ from baseline.

Abbreviations: CG, control group; ExG, exercise group; ExG+PrG, combined exercise and protein supplementation group; PrG, protein suplementation group; SD, standard deviation; s, seconds. 
muscle strength), the highest increment was observed in the ExG (47.6\%), followed by the Ex+PrG (38.4\%) and PrG (36.7\%) as compared with the CG $(-10.9 \%)$ (Figure 2$)$. In the 8-Foot Up and Go Test, the PrG $(-2.3 ; 28.3)$ showed the highest reduction for this test, followed by the $\mathrm{Ex}+\operatorname{PrG}(-2.2$; $26.6 \%)$ and ExG $(-1.9 ; 21.7 \%$ ) (Figure 3$)$. However, the CG $(+1.3 ; 1.2 \%)$ showed an increment in the 8-Foot Up and Go Test as compared with baseline. This study also found that the Chair Sit and Reach Test, Backscratch Test, six-minute Walk Test, and the Handgrip Strength Test remained unchanged throughout the 12-week intervention $(P>0.05)$.

\section{Intervention effect on the oxidative stress}

Table 4 shows a significant group effect $\left(F_{3,61}=2.969\right)$ $(P<0.05)$ and time effect $\left(F_{3,61}=3.777\right)(P<0.05)$ for protein carbonyl. A decrease in protein carbonyl levels after the 12 -week intervention was observed in the ExG+PrG $(-0.01[50 \%])$ and $\mathrm{CG}(-0.01[33.0 \%])$ as compared with baseline. Further, only the ExG+PrG (-0.01 [50\%]) showed a reduction in protein carbonyl levels at 12 weeks as compared with the $\mathrm{CG}$.

On the other hand, SOD levels showed a significant time effect $\left(F_{3,61}=9.276\right)(P<0.05)$ and an interaction effect $\left(F_{3,61}=5.963\right)(P<0.05)$ after 12 weeks of intervention (Table 4). An increment of mean changes was observed in the PrG (+5.2 [91.2\%]) and $\mathrm{CrG}(+1.7$ [22.9\%]). However, SOD levels decreased in the ExG (-3.9 [38.2\%]) after 12 weeks. In comparison with the CG, an increase in SOD levels was observed in the ExG $(+0.3$ [5.7\%]) and PrG (+0.3 [5.7\%]). Meanwhile, the ExG+PrG $(-0.9$
[34.6\%]) showed no changes in SOD level after 12 weeks of intervention. For lipid hydroperoxide, a significant group effect $\left(F_{3,61}=4.098\right)(P<0.05)$ and a time effect $\left(F_{3,61}=3.244\right)(P<0.05)$ were noted (Table 4$)$. An increment in mean was observed only in the ExG+PrG $(+1.2[81.9 \%])$; whereas the PrG (-0.7 [19.1\%]), ExG (-0.1 [5.1\%]), and the CG (-1.3 [38.2\%]) showed a decrease in lipid hydroperoxide levels as compared with baseline. In comparison with the $\mathrm{CG}$ at 12 weeks, the $\operatorname{PrG}(+0.7$ [31.6\%]), ExG+PrG (0.6 [26.0\%]), and ExG (+0.3 [12.1\%]) showed an increment in lipid hydroperoxide levels. The IGF-1, IL-6, and orexin markers remained unchanged throughout the 12 -week intervention.

\section{Discussion}

This study is one of a few studies reporting the effects of a community-based, well-rounded exercise program and protein supplementation, either alone or in combination, among elderly people with sarcopenia. First, having examined the effects on body composition, the PrG showed the highest reduction in body weight and BMI after 12 weeks of intervention. These findings contradicted a previous study in which body weight and BMI did not change following soy supplementation for 12 weeks among hyperlipidemic males. ${ }^{24}$ This may be due to a higher dosage of protein supplementation provided in the current study (to achieve a daily protein intake of $1.5 \mathrm{~g} / \mathrm{kg} /$ day) compared with that study. ${ }^{24}$ However, this present study was unable to demonstrate the beneficial effect of protein supplementation in fat-free mass. This is also in contrast with another study that showed an improvement in fat-free mass of about $2.4 \%$ after 12 weeks of intervention with amino acid supplementation. ${ }^{14}$ This study

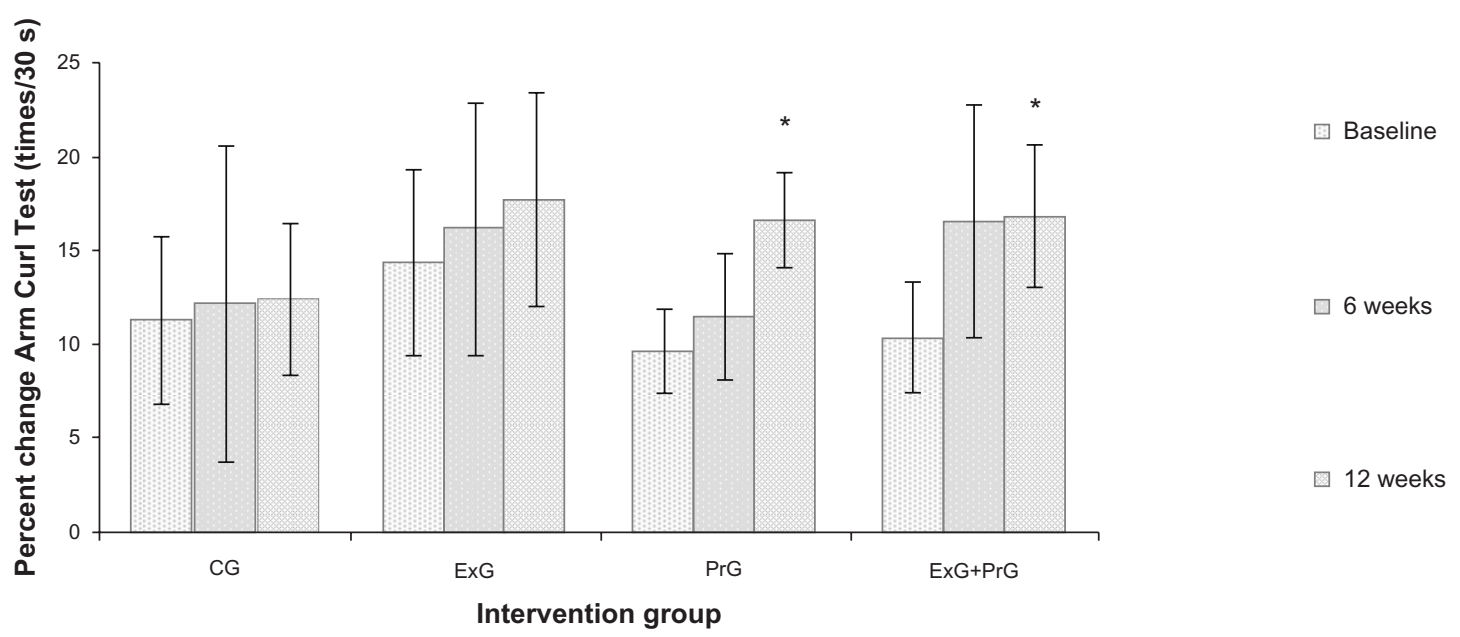

Figure 2 Percent changes in Arm Curl Test results, in the different intervention groups during the I2-week intervention. Notes: Values are expressed as mean \pm SD. *Significant differences at $P<0.05$ from baseline.

Abbreviations: CG, control group; ExG, exercise group; ExG+PrG, combined exercise and protein supplementation group; PrG, protein suplementation group; $\mathrm{SD}$, standard deviation; s, seconds. 


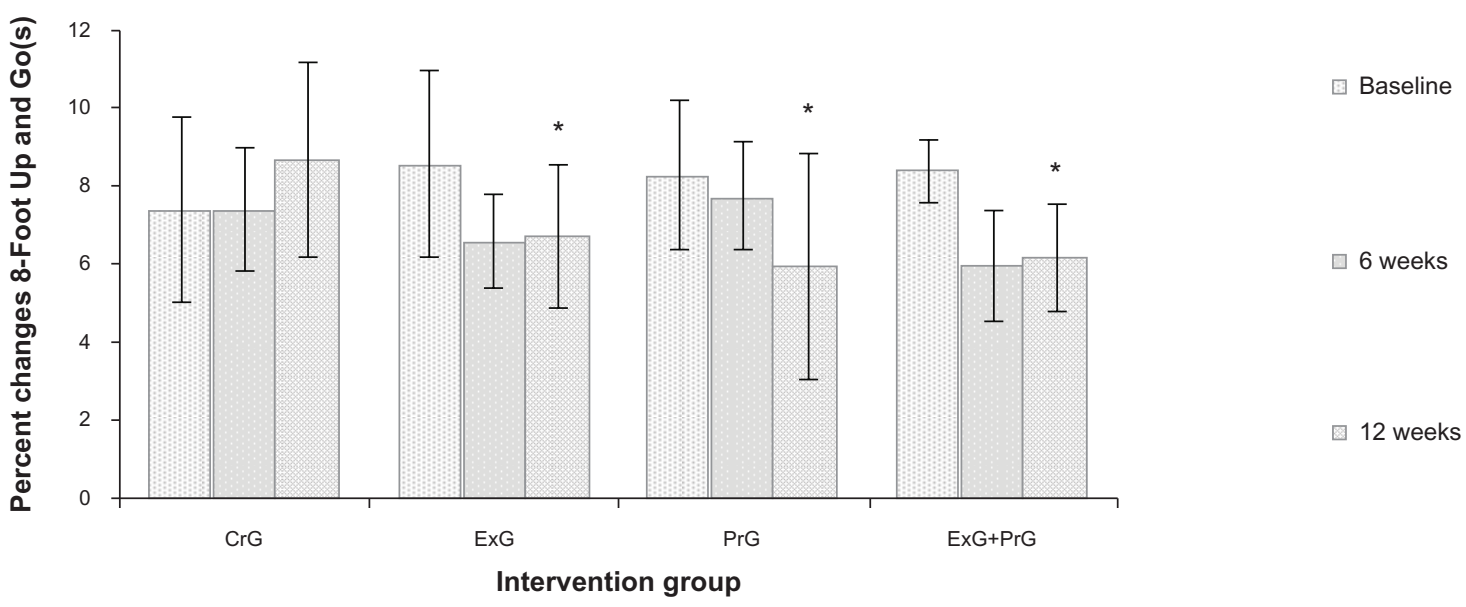

Figure 3 Percent changes in 8-Foot UP and Go Test results, in the different intervention groups during the I2-week intervention. Notes: Values are expressed as mean \pm SD. *Significant differences at $P<0.05$ from baseline.

Abbreviations: CG, control group; ExG, exercise group; ExG+PrG, combined exercise and protein supplementation group; PrG, protein suplementation group; SD, standard deviation.

was also inconsistent with previous research that showed an improvement in fat-free mass by about $2.4 \%$ after 12 weeks of intervention with amino acid supplementation. Here, the discrepancy might be due to the higher composition of leucine ( $40 \%$ of the total amino acid) in that study as compared with $28.8 \%$ in the present study. ${ }^{14}$ However, our findings were in agreement with a study done in Japan in which the well-rounded exercise (three times per week) groups showed a tremendous reduction in percentage of body fat. ${ }^{25}$ This study also found no significant changes in muscle mass in all intervention groups after the 12 -week intervention. However, there was a trend of improvement in muscle mass for the ExG and ExG+PrG. Thus, it is necessary to identify optimum duration and intensity of exercise that might give significant changes in body composition.

Upon completion of this study, it was observed that the use of a community based well-rounded exercise program combining low intensity and resistance exercise improved the physical function test results with respect to muscle strength and both upper and lower body strength. It was also noted that the ExG showed the highest improvement in upper body strength, and the PrG in lower body strength. Other researchers have reported that resistance exercise training with optimum intensity and duration can improve functional fitness in older adults. A study done by Yamauchi et $\mathrm{al}^{4}$ of a 12- and 24-week intervention with a well-rounded exercise program, consisting of aerobics, resistance exercise, and stretching exercise, among 23 older adults showed improvements in upper and lower body strength, agility, and flexibility, which is in line with the findings of the current study. In Japan, the beneficial effects of resistance training using elastic bands in combination with aerobic exercise or balance exercise were studied; ${ }^{21}$ in that study, 113 older adults were assigned to different groups with different modes of exercise: a resistance exercise group, a balance exercise group, a flexibility exercise group, a tai chi exercise group, and an aerobic exercise group. During the 12-week intervention, the resistance exercise group showed the highest improvement in upper body strength, while the balance exercise group showed improvement in lower body strength. ${ }^{16}$ Another study highlighted the benefit of resistance training in preventing muscle loss, and it was noted that resistance training could incur strength gains in older adults ranging from $25 \%$ to $100 \%$, or more, through muscle hypertrophy and increased motor unit recruitment. ${ }^{26}$

In addition, this current study investigated the changes in the oxidative stress parameters following the 12-week intervention. Reactive oxygen species (ROS) could play a role in triggering sarcopenia, as reported by Fulle and Fano. ${ }^{10}$ The researchers noted that the senescence of skeletal muscle was characterized by a significant decrease in endogenous antioxidant mechanisms, with a consequent increase in oxidative damage, which was directly correlated with a functional deficit in the control of $\mathrm{Ca}^{2+}$ homeostasis by myofibers. ROS altered the opening capacity of sarcoplasmic reticulum. ${ }^{12}$ In this current study, the reduction of SOD enzymes was observed in the ExG; no changes were observed in the ExG+PrG, indicating the beneficial effect of exercise in suppressing free radicals that occur during exercise, and causing SOD, which acts as a free radical scavenger, to be reduced. The levels of antioxidative enzymes were increased in the PrG. This is in line with the study done by Fulle et a ${ }^{10}$ 


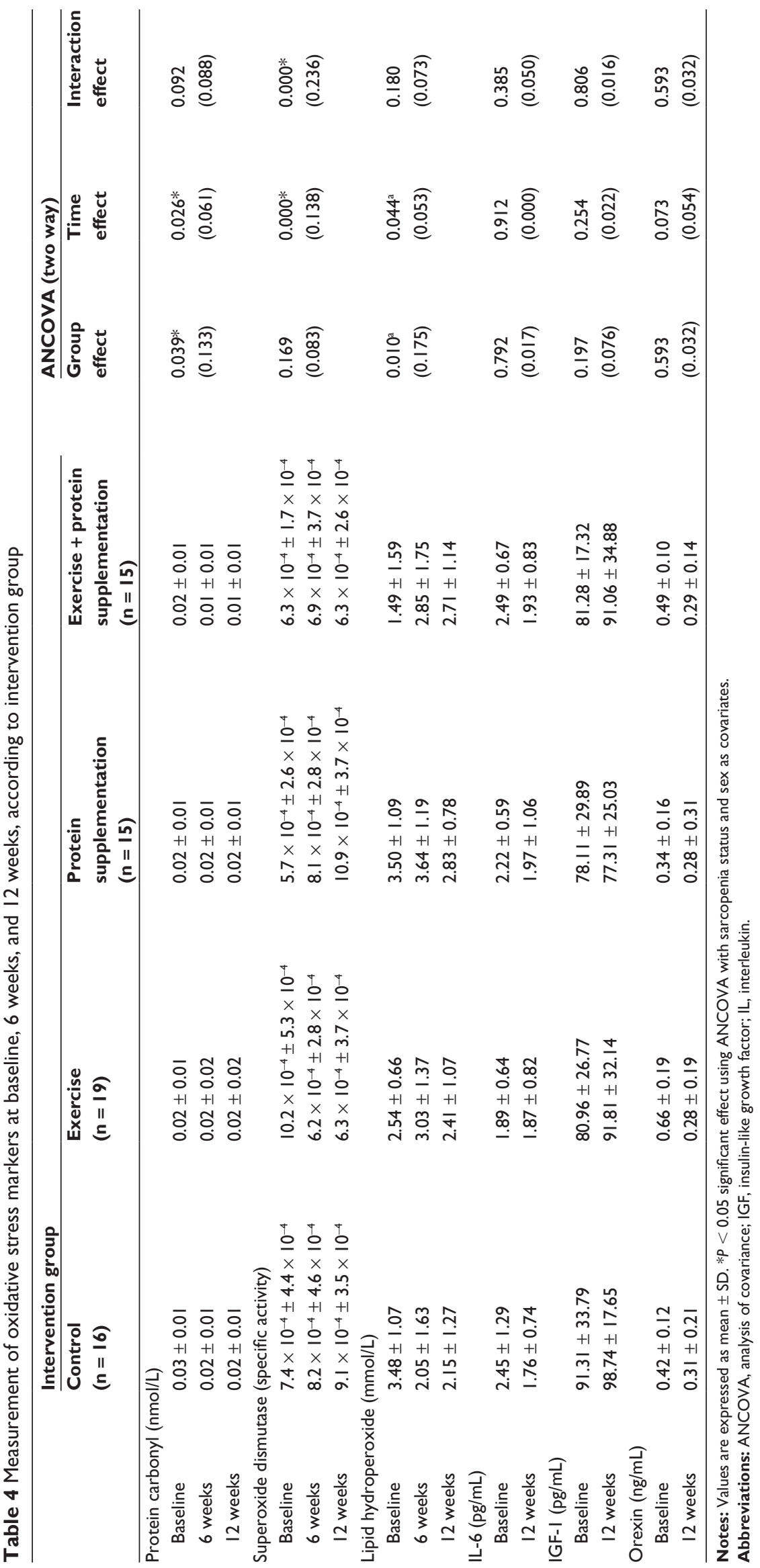


who noted a decrease in the antioxidative capacity of the main scavenger enzymes during exercise. However, protein carbonyl and lipid hydroperoxide did not show any significant changes in either intervention group. These findings suggest that both exercise and protein supplementation were unable to modify the lipid and protein oxidation levels, in this study.

There is growing evidence that the reduction of (IGF)-1 related to aging plays a role in the pathogenesis of sarcopenia. A previous study reported an IGF-1 increment of 37\% in Brazilian women aged 45-70 years old, after 16 weeks of resistance training. ${ }^{26}$ This finding contradicts our findings, which did not show any changes throughout the 12-week intervention. This may be due to the lesser frequency of exercise in the program in our study - only two times per week for 12 weeks as compared with the previous study, which had exercises three times a week for 16 weeks. ${ }^{21}$ On the other hand, the causal pathway leading to inflammation and disability may cause decline in functional ability. Thus, the assessment of the IL-6 levels may be considered as one of the indicators to measure the influence of inflammation, in this intervention study. ${ }^{27}$ Notwithstanding this, IL-6 levels remained unchanged throughout the 12-week intervention. Findings from Kohut et $\mathrm{al}^{28}$ suggested that the type of exercises performed may impact the extent to which serum inflammatory markers were altered. Cardiorespiratory exercise could probably reduce serum IL-6, whereas flexibility/ moderate strength training did not have the same positive effect. ${ }^{26}$ In the current study, more emphasis was put on the flexibility and moderate strength exercises, which may not have any effect on IL-6 levels.

The sex distribution could have played a significant role in the determination of changes in the parameters study, due to the discrepancy in the metabolism and physiological mechanisms in the body system of men and women. However, in this study, a two-factor ANCOVA was used to compare the body composition, functional fitness, and oxidative stress between intervention groups, controlling for sex, which was not of primary interest. Thus, the unequal distribution of sex in this study did not affect the parameters studied.

One of the strengths of the current study is that the participants were noninstitutionalized, and therefore, this may allow direct extrapolation of the results to older persons of the local population. Physical activity stimulates muscle protein synthesis and accelerates protein breakdown. Protein supplementation is required to inhibit protein breakdown and stimulate protein synthesis, resulting in a positive muscle protein balance. The combination of both exercise and protein supplementation were important and could give better effects in enhancing muscle protein synthesis compared with exercise and protein supplementation alone. ${ }^{29}$ The major limitation of the study is that bioelectrical impedance analysis was used to estimate muscle mass, whilst previous studies have noted inaccuracies in its use to assess fat-free mass in the elderly - this was thought to be due to the changes in the hydration of fat-free mass and the cylindrical shape of the appendicle muscle. ${ }^{5}$ Furthermore, the timing of protein ingestion should be standardized to maintain the optimum absorption of protein supplements in the subjects. In addition, the study was not a randomized clinical trial. This could have reduced the statistical power of the study and increased bias. However, at baseline the confounding factors were identified and were taken into consideration during the analysis of the intervention.

\section{Conclusion}

This study showed that exercise intervention and protein supplementation were beneficial in both reducing body weight and improving fat-free mass. There were no effects seen on muscle mass during the 12-week intervention. Further, the intervention seems to have been effective in improving upper and lower body strength as well as agility and dynamic balance among the subjects. These improvements are desirable for increasing mobility and quality of life of the elderly. On the other hand, the exercise intervention may have acted as a scavenger and reduced the antioxidative enzymes, but it did not alter the lipid and protein oxidation in this study. Protein supplementation seems to have increased the antioxidative enzymes in this study. Moreover, there was no effect on hormones and inflammatory markers observed in this study. It would be interesting to investigate the effects of other dietary interventions, such as the inclusion of a high protein diet through natural food sources, in the sarcopenic elderly. Taking into consideration the benefit of exercise and protein supplementation, a well-planned intervention program could reduce the incidence of sarcopenia in the elderly, and should be introduced. This could reduce the health care cost attributable to sarcopenia worldwide and increase longevity.

\section{Acknowledgments}

The authors thank the participants for their voluntary involvement in this study. In addition, the authors acknowledge the financial assistance from the Ministry of Science Technology and Innovation, who sponsored this study (research grant 06-01-02 SF 0551). 


\section{Disclosure}

The authors report no conflicts of interest in this work.

\section{References}

1. Doherty TJ. Invited review: aging and sarcopenia. J Appl Physiol. 2003;95(4):1717-1727.

2. Evans WJ. Skeletal muscle loss: cachexia, sarcopenia, and inactivity. Am J Clin Nutr. 2010;91(4):1123S-1127S.

3. Bijlsma AY, Meskers CG, Westendorp RG, Maier AB. Chronology of age-related disease definitions: osteoporosis and sarcopenia. Ageing Res Rev. 2012;11(2):320-324.

4. Yamauchi T, Islam MM, Koizumi D, Rogers ME, Rogers NL, Takeshima N. Effect of home-based well-rounded exercise in community-dwelling older adults. J Sports Sci Med. 2005;4(4):563-571.

5. Janssen I, Baumgartner RN, Ross R, Rosenberg IH, Roubenoff R. Skeletal muscle cutpoints associated with elevated physical disability risk in older men and women. Am J Epidemiol. 2004;159(4):413-421.

6. Lee JS, Auyeung TW, Kwok T, Lau EM, Leung PC, Woo J. Associated factors and health impact of sarcopenia in older chinese men and women: a cross-sectional study. Gerontology. 2007;53(6): 404-410.

7. Dreyer HC, Volpi E. Role of protein and amino acids in the pathophysiology and treatment of sarcopenia. J Am Coll Nutr. 2005;24(2): 140S-145S.

8. Stenholm S, Harris TB, Rantanen T, Visser M, Kritchevsky SB, Ferrucci L. Sarcopenic obesity: definition, cause and consequences. Curr Opin Clin Nutr Metab Care. 2008;11(6):693-700.

9. Woods JL, Iuliano-Burns S, King SJ, Strauss BJ, Walker KZ. Poor physical function in elderly women in low-level aged care is related to muscle strength rather than to measures of sarcopenia. Clin Interv Aging. 2011;6:67-76.

10. Fulle $\mathrm{S}$, Fanò $\mathrm{G}$. The contribution of reactive oxygen species in sarcopenia and muscle aging. In: Stocchi V, De Feo P, Hood DA, editors. Role of Physical Exercise in Preventing Disease and Improving the Quality of Life. Milan: Springer; 2007:103-111.

11. Nied RJ, Franklin B. Promoting and prescribing exercise for the elderly. Am Fam Physician. 2002;65(3):419-426.

12. Visvanathan R, Chapman I. Preventing sarcopaenia in older people. Maturitas. 2010;66(4):383-388.

13. Peterson MD, Rhea MR, Sen A, Gordon PM. Resistance exercise for muscular strength in older adults: a meta-analysis. Ageing Res Rev. 2010;9(3):226-237.

14. Paddon-Jones D, Sheffield-Moore M, Katsanos CS, Zhang XJ, Wolfe RR. Differential stimulation of muscle protein synthesis in elderly humans following isocaloric ingestion of amino acids or whey protein. Exp Gerontol. 2006;41(2):215-219.
15. Wolfe RR, Miller SL, Miller KB. Optimal protein intake in the elderly. Clin Nutr. 2008;27(5):675-684.

16. Carlsson M, Littbrand H, Gustafson Y, et al. Effects of high-intensity exercise and protein supplement on muscle mass in ADL dependent older people with and without malnutrition: a randomized controlled trial. J Nutr Health Aging. 2011;15(7):554-560.

17. Børsheim E, Bui QU, Tissier S, Kobayashi H, Ferrando AA, Wolfe RR. Effect of amino acid supplementation on muscle mass, strength and physical function in elderly. Clin Nutr. 2008;27(2):189-195.

18. Shahar S, Earland J, Abdulrahman S. Validation of a dietary history questionnaire against a 7-D weighed record for estimating nutrient intake among rural elderly. Malays J Nutr. 2000;6(1):33-44.

19. Katsanos CS, Kobayashi H, Sheffield-Moore M, Aarsland A, Wolfe RR. A high proportion of leucine is required for optimal stimulation of the rate of muscle protein synthesis by essential amino acids in the elderly. Am J Physiol Endocrinol Metab. 2006;291(2):E381-E387.

20. Jones CJ, Rikli RE. Measuring functional fitness in older age. The Journal on Active Aging. 2002;1:24-30.

21. Takeshima N, Rogers NL, Rogers ME, Islam MM, Koizumi D, Lee S. Functional fitness gain varies in older adults depending on exercise mode. Med Sci Sports Exerc. 2007;39(11):2036-2043.

22. Beyer WF, Fridovich I. Assaying for superoxide dismutase activity: some large consequences of minor changes in conditions. Anal Biochem. 1987;161(2):559-566.

23. Buss H, Chan TP, Sluis KB, Domigan NM, Winterbourn CC. Protein carbonyl measurement by a sensitive ELISA method. Free Radic Biol Med. 1997;23(3):361-366.

24. Carol D, Harold B, Peter H, John L, Richard B. Resistance training with soy vs whey protein supplements in hyperlipidemic males. $J$ Int Soc Sports Nutr. 2009;6:8.

25. Nakamura Y, Tanaka K, Yabushita N, Sakai T, Shigematsu R. Effects of exercise frequency on functional fitness in older adult women. Arch Gerontol Geriatr. 2007;44(2):163-173.

26. Orsatti FL, Nahas EA, Maesta N, Nahas-Neto J, Burini RC. Plasma hormones, muscle mass and strength in resistance-trained postmenopausal women. Maturitas. 2008;59(4):394-404.

27. Schaap LA, Pluijm SM, Deeg DJ, Visser M. Inflammatory markers and loss of muscle mass (sarcopenia) and strength. Am J Med. 2006;119(6):526. e9-526. e17.

28. Kohut ML, McCann DA, Russell DW, et al. Aerobic exercise, but not flexibility/resistance exercise, reduces serum IL-18, CRP, and IL-6 independent of beta-blockers, BMI, and psychosocial factors in older adults. Brain Behav Immun. 2006;20(3):201-209.

29. Bonnefoy M, Cornu C, Normand S, et al. The effects of exercise and protein-energy supplements on body composition and muscle function in frail elderly individuals: a long-term controlled randomised study. Br J Nutr. 2003;89(5):731-739.
Clinical Interventions in Aging

\section{Publish your work in this journal}

Clinical Interventions in Aging is an international, peer-reviewed journal focusing on evidence-based reports on the value or lack thereof of treatments intended to prevent or delay the onset of maladaptive correlates of aging in human beings. This journal is indexed on PubMed Central, MedLine, the American Chemical Society's 'Chemical Abstracts Ser-

\section{Dovepress}

vice' (CAS), Scopus and the Elsevier Bibliographic databases. The manuscript management system is completely online and includes a very quick and fair peer-review system, which is all easy to use. Visit http://www.dovepress.com/testimonials.php to read real quotes from published authors. 